\title{
Timescapes in Academic Life. Cubicles of Time Control
}

\author{
Ida Sabelis
}

\begin{abstract}
Under current conditions, it seems not enough to construct a plea for 'slow science'. Temporalities of academia under TINA require close scrutiny in order to bring out the time regimes of academic life. Economy, efficiency, and effectiveness have produced measures by which not only work processes are uniformized and controlled, but especially the design, the character, and the pace of work, including the embodied experience of working. Consequently, (academic) work determines a lot of other aspects of our existence and it tends to uniformize work load as a given. The image arises of not only $24 / 7$ availability for academic work, but the inevitability of compliance to working in individual bubbles of time control, causing a narrower focus for 'the academic' and possibly less space for the rhythms of academic creation and creativity. Autobiographical 'vignettes' illustrate this development, highlighting the working of regimes that are not questioned on a daily basis.
\end{abstract}

\section{Keywords}

timescapes - Bildung - education - time regimes - workload - work-life balance

\section{Introduction}

In the opening scene of the film About Smith (2002), we see how Smith/Jack Nicholson waits. He sits, fully dressed in his winter coat, briefcase on his lap with his hands folded on top. The camera cuts to the clock over the door. We see the hour hands move, tick, tick, tick... the hour hand reaches five, the minute hand twelve, until exactly five pm. As if he feels that the time he has waited for has arrived, Smith just gets up and walks out the door, on to his retirement. A final leave? - or just what he always does: he leaves at exactly five o'clock, a neat split between work and other parts of his life. But he leaves, seemingly 
with clock time internalised, as if an inner metronome permits him to change scenes.

This scene has been with me since I first saw it; I could forget other details of that film, but this... Why did it stay with me in all clarity? It could be the punctuality associated with professional life - for a certain type of profession, that is. It could be the breath-taking tension caused by presenting work time and space in this manner. Or maybe it's also the immense experience of a tempo-spatial marker between working life, and - what, another life? or even retirement as a definitive phase, perhaps more than any other phase instilled with irreversibility? There is no going back after retirement - only old age, decline, and death await: a clock reaches five, and the cage of the office opens to freedom. Professional identity, so important in our type of society, is gone from literally one minute to the next. Smith does not seem to regret it - he is about to start a new life, liberated from work and from the straitjacket of working time. Most of all, I contend, this scene represents a timeframe of work that we do not experience anymore: work is, or was, an activity bound to an office and certain times of the day; it used to be a solid marker of life's activities (Elias, 1982/1985). Times and places for work and private life - rhythms of days, weeks, months, and years were embodied parts of our life's rhythmicity. Steady, and reliable, providing a pace of life.

Increasingly now, neither the office nor set times for work guide our working days, especially not in academia and other free professions (Lorenz, 2012). Economy, efficiency, and effectiveness have produced measures by which not only work is controlled, but especially the design and the character of work, including the embodied experience of working, and al lot of other aspects of our existence in its wake. Office times meander right through the times we spend at home, or on vacation, or wherever else in the world. Working times, in the 1990s problematised from the perspective of 'tele-work' (Paolucci, 1996) can hardly be set apart from 'other times'. Telework has developed into the experience of being 'always on'; it is not just an extra option to follow up on tasks, or work from home from time to time, it has established itself fully as the norm. Telework was succeeded by 'new ways of working', a specific type of open office use applied at random for a more efficient use of workspaces over time. ${ }^{1}$ At the root of this development seems to be an increase in both standardisation and control of work, partly driven by technology, but mainly by the primacy of economics and an attitude based on consumerism (Parker \& Jarvey, 1995; Ritzer, 1996; Roderick, 2016) as a consequence of what is called the neoliberal

1 And yes, perhaps 'new ways of working' are an expression of recent changes in working time imperatives. It is hard to pinpoint what was first, and how working time/s and New Ways of Working (HNW) feed into each other. 
turn (Van der Pijl, 2006; Davies et al., 2006; Lorenz, 2012). Of course, not all organisations produce or demand office times and spaces, but our society does require a lot of 'office work' in the form of service institutes and maintenance organisations providing supervision and control. Higher education and academia especially seem to produce and require offices under the guise of the growing importance of education (in the form of institutes of higher education) as a commodity, along with an increase in bureaucracy as a format to control the times of the people in it, as a function of the desired output.

Meanwhile, Martha Nussbaum, in her book Not for Profit (2010) argues along similar lines, adding that the humanities' purpose to promote reflection, critical thinking, creativity, and an interest in what cannot be predicted (or measured) must be pruned and curbed in a society that requires quantification as proof (of the benefits, the 'truth') and that ultimately serves the bureaucracy of the sciences and academic life. ${ }^{2}$ And it is exactly this bureaucracy, with its time-consuming systems, that needs to be fed, and the promise of equal international comparison and competition ${ }^{3}$ that ultimately takes up so much time that the raison-dêtre of universities is called into question. ${ }^{4}$ There is some kind of a niche in academia comprised of authors writing and complaining about these changes. And there is a vast body of work about neoliberal ways of higher education. But one of the main problems seems to be that nothing really changes the way things are going. Bauman and Donskis (2013) argue how this development is linked to ongoing managerialism. Academia seems to be contextualised and pervaded by a closed circuit: changes are announced with the argument that there is no money to act otherwise - and that changes provide real chances for revision, reflection, and improvement in education and research alike. A case of TINA, as Donskis and Bauman would put it; there is no alternative, thus compliance to the new, and this closed circuit is inescapable. Nobody dares to resist an opportunity to improve, of course. But the message of change also triggers ambiguity - ongoing change implies that 'things were never right', causing fear and insecurity, which in turn invites even faster change. No change, no progress as the saying has it; but even that expression has a different feel to it, as it has become a seemingly unquestioned, driving force. As Bauman and Donskis put it: 'Permanent change becomes a perfect form of social control' (2013, p. 139). What does that mean on a daily basis for academics, and what does that mean for the development of academic knowledge?

2 See also Kamsteeg in this volume.

3 See also Bianchini in this volume.

4 I use higher education, universities, and 'academia' alternatingly: HE, where mere education is meant, academia for the combination of education and research (knowledge production). 
- Morning: try to make my desk free of tasks to be able to think. I start out by reading, responding, and filing emails.

- Some replies can be quick, just a note, but some take more time, or postponed action. In between, it seems better to make some phone calls. And, while working at home, the to-do-list also entails some domestic chores: dentist appointment for next week, neighbour with a query, some private emails to respond to.

- I phone a colleague about a research project and add some tasks to the main to-do-list.

- A colleague phones about a deadline - I deflect the process by involving another colleague.

- Then the main task begins: reviewing for the international journal I am involved with. The Manuscript Central system shows some 8 new articles to be desk reviewed, another 4 to 6 papers in the review process that need to be checked for delays, for paper to be accepted, and some correspondence with the central secretariat.

- After four hours I have ticked nine different tasks, and still feel as if I have not really done important work. Chores, small duties, but no real thinking, let alone reading.

- Have to switch off the automatic email notification. But also have to be available for the workers' council, in which the annual budget has its own rhythm. Hurry to read the documents for tomorrow's meeting small notes, a glancing over them, and a little walk to think things over.

- Email again - I forgot to send an honorarium application after a PhD committee. Should not forget to send a card to congratulate.

- Project team calls for signed letter - forward the message to an assistant.

- Check Uni's central system for tasks - and find a course evaluation that needs response. Put on to-do-list for later this week.

- Evening: almost ten working hours spent.

- Exhausted - allow myself a little Netflix to unwind.

- Hot tea and early (?) to bed.

- Note: the main thing is not the character of the work, but the constant switching of scenes, of required energy, of starting again with never any relief after finalising - next thing already there. It is like a bicycle trip with too many traffic lights: constant acceleration, too many stops, no flow.

IS- summary from to-do-lists 
If we feel so stressed, if so many colleagues report being 'always on', and if indeed we cannot escape giving in to the consumerist demand to think of knowledge and education as products totally subjected to market demands on a global scale, it seems pivotal to look at how this has become normalised and negotiated, and maybe even neglected, in our time use and perception. Of course, acceleration, the striving for moving ever faster, plays a role here. But that is not the only thing; other temporal traits are involved in terms of the neglect of long-term effects and immediate health risks (Clegg, 2010). Therefore, in this chapter, I propose to look at academia from a timescape viewpoint (cf. Adam, 1998; Sabelis, 2002), going beyond the mere analysis of acceleration and the call to slow down (Wels, this volume; Mountz et al., 2015). This requires looking at the education process with some reflections on 'Bildung', understood as classical Humboldtian education with specific assumptions about the temporalities of learning and knowledge production; and for the part of knowledge development (if not production), I will take a look at the experience in the work of colleagues who have researched the increasing time pressures and desperation of academics in the context of growing workloads and shifting temporalities. Together with some vignettes that serve as autobiographical reflection, this will then provide a view of how our total time experience is changing, our senses for temporalities curbed and controlled partly by the digitalisation of just about everything, and partly by the inescapability of control mechanisms setting the paces of our work and lives.

\section{$2 \quad$ Bildung / Education in Terms of Time}

One of the core tasks of universities is the education of students on to an academic level, either for further study as academics or for necessary life luggage for work and career. This notion of education is nicely illustrated via the German concept of Bildung, which is an activity engaged in via different, not always prognosticated temporal elements. ${ }^{5}$ In this concept, relationships between learning, reflecting, acquiring certain ways of thinking, and especially coming up with new questions is of paramount importance. Bildung has no satisfactory direct translation into English; it derives from a 'romantic' ideal, a middle-class appeal for emancipation via education (see, for instance, Oelkers, 1999). Bildung covers education, but is generally speaking a far broader concept. A polite or civil person (gebildet in German) may have had a good education, or a great deal of education, but this is not always necessary - at least not in the

5 Some of what is written here derives from my former career in the realm of Bildung (organisational consultancy, general education). See also Abrahám in this volume. 
sense of school or university education. Bildung/education in the classic sense seems to refer to both temporal as well as normative social qualities that are acquired to be (become) a valuable member of society. Obviously Bildung in this sense takes time and provides time; the latter in terms of enabling a broader horizon of insights for the proper assessment, analysis, and enacting of the knowledge and skills to be a citizen. But what is the relationship to time when reflecting on Bildung/education? Just a switch in perspective, from contemplation to reflection, to planning, constitutes far too brief a summary of how the historical development of Bildung/education can be seen. Let us look at a take on Bildung/education from different time perspectives: its relationship to pastpresent-and-future, its different rhythms and requirements of time elements or timescales, the role of tempo in terms of fast and slow, and its Eigenzeiten, the inherent social/physical temporal dimensions that belong to the different, mutually implicating elements of Bildung.

A specific, socially relevant issue regarding Bildung/education is that it has a relationship to past, present, and future, not just producing 'knowledge' on the spot for today or next week only. Bildung/education prepares for a future context as well; it makes envisioning and planning possible, or avoidable for that matter, for various futures through the accumulation and intrinsic connectivity of knowledge. A specific aspect to remember here is that both the content and the learning systems derive from past experience, 'what worked well', but are geared towards the future, 'what will come of this'. Thus, a crucial element in educational systems is that we use the past to provide for, or at least take account of possible futures, while we more or less consciously produce or prevent futures in our present (Adam \& Groves, 2007). We may wonder if and how this works in its present form(s), as well as in the current guise of being promoted via neoliberal assumptions of 'usefulness' and efficiency.

\section{Vignette 2: TALK TO A FRIEND}

When I started out as an academic, the educational programme attracted more students than we could staff. I learned to work fast, and sometimes graded theses in an hour, just to help out a colleague. I liked the tension, the stress, and the pride in succeeding in those tasks. But before we knew it that type of hurried working became the norm. It is tempting sometimes to sit back and read interesting work by students, but that just takes too much time - the new systems we work with assign hours to tasks; and thus, we face an accumulation of tasks based on what can be measured against the money the university makes available. With this, our time has 
become measured, controlled, and accounted for. We have fixed times for different tasks now. This actually means that a lot is not calculated in, and this heightens the pressure.

Another Rhineland concept, that of Eigenzeiten, or 'proper times' (Nowotny, 1992), can be helpful here. It refers to the inherent (system) times necessary to 'keep things going'. In other words, how, for instance, children and adults need different amounts of time, different rhythms, sequences, duration, and paces for various tasks, especially in education and learning activities. We all know how different chunks of knowledge require different paces; for instance, learning a language requires learning by heart, and a lot of repetition and pure use. While learning to do math requires, apart from choosing an area (algebra, goniometrics, calculations, differential equations), deep and 'criss-cross' thinking, following certain systems, and enjoying solving puzzles. Obtaining a certain level of critical thinking again demands different paces, learning cycles, periods of thought and reflection, and time for the ripening of insights. Basically, learning times/times for learning are the first time dimensions that teach us how there 'is a time for everything', for pace and rhythms of learning, for short- and long-term memory, for the role of accumulation of knowledge, and for the combination, deepening, expanding and sometimes also the loss of certain types of knowledge. This is also coupled with different times of day, week, or year (seasons) that are considered better or less proper for various activities of learning and study. It is a lot more difficult to be up and about reading and thinking early in the morning when it's winter rather than summer. And, to add a dimension, this is again different for owls and larks, or morning and evening people. All thinkable contextual and inner details together build conditions for learning in different combinations, on group (school/cohort) level, as well as for individuals.

Additionally, the concept of timescales links up with the variation of thinkable temporalities (Kümmerer, 1996; Lemke, 2001) inherent in both teaching and learning. Some timescales are pretty much fixed, such as heart rate; the maturing process of different animals, trees, and plants; the life cycles of various species; or the times required to obtain certain types of knowledge and skill. There is also some flexibility or resilience that allows one to cope with unexpected changes in a system; this illustrates that rhythmicity and cyclicality never refer to the same but always to the more-or-less similar, an important distinction to remember because the suggested space in more-or-less similar allows for resilience and sets rhythmicity apart from metronomic tact (Young, 1988; Adam, 1995). Time compression is only possible if rhythmicity is 
acknowledged, if there is room for variation, for a periodic 'free flow', and, at other times, for pressure (Sabelis, 2002). Because everyone has his or her own personal rhythms, educational systems will enable learning for some, while hindering it for others (e.g. morning and evening people, but also related to the changing of seasons, age-related differences, and personal combinations of adaptability and creativity). If we think about learning in this manner, we are all somehow aware of our personal rhythms that often turn out to be at odds with the social rhythms required of us by society. On the one hand, we choose to participate in societal activities that we like or need, while, on the other, social activities create a necessary evil - such as obligations or 'culturally defined times', among other things. Nothing wrong with deadlines and schedules until one's slow pace becomes a problem or when acceleration leads to stress (Rosa, 2003). In these cases, we end up suddenly having to take 'time out' in the form of a holiday or an illness, so we can check to see what is going on and what needs to be changed to prevent inefficiency or a burnout. Yet, increasingly, because of neglect of Eigenzeiten and personal temporal needs under clock-time working conditions, the result is burnout or neglecting one's sense of balance in the everyday pace of our lives; our sense of time becomes confused and a sense of pressure tends to dominate. How time perception is learned is easily observed with children, who sometimes combine time elements in unexpected ways. When she was four, my daughter once commented, 'Mum, you have to buy time', referring to the fact that I had to put money in the parking meter. Indeed, as small children learn about time, they often make us aware of the tensions involved in how we use time in our daily lives.

In sum, Bildung/education, as learning, developing, forming, preparing, sustaining, building, and combining essential elements of survival, knowledge, interest, curiosity, and then conjoining those elements in useful ways in (and for) specific situations, requires different, embodied ways of time perception and time spending, sometimes slow and sometimes fast. Education as a way to open us up to certain areas, while also focussing on others; it enables or hinders us in our goals based on particular physical, psychological, and systematic conditions present. In other words, Bildung/education provides knowledge in the widest sense, to be used according to one's need, and it allows us to see how Eigenzeiten, as the various times that comprise the total of our interrelated temporalities, are threatened, or how they build a reliant framework for action and preparation. Maybe we could even state that Bildung/education in its multiple qualities is closely related to resilience. These qualities emerge not only in how human beings learn - in the broadest sense of acquiring skills and knowledge - but also how people use a multitude of strategies and ways, which they combine in sometimes very complex short- and long-term ways to 
produce insights and skills that help make sense of our lives and provide logic for others.

Bildung/education deals with our own personal survival and maintenance, as well as that of the society we are part of. So, what happens if we compress and rationalise that vast vision of learning, what happens if we can only see a standardised mode of time for learning and reflection? It is one thing to accept that Bildung/education reflects the needs of the society it serves, but what if this brings along with it vast uniformization, and what if it more or less discourages queer (out of the box) or serendipitous thinking, or even dismisses that as superfluous under neoliberal conditions? More importantly, what if, as Zygmunt Bauman suggests (Bauman \& Donskis, 2013, p. 134), utopia, the ideal society, has become privatised into a space where we all strive for our own individual success stories, rendering Bildung superfluous as long as the audits are all right? Acceleration of work processes and fluidity of relationships present a picture where we do not even need Bildung/education, since the rational frames and context promise almost ready-made career paths, like fast food for the mind.

\section{$3 \quad$ Timescapes of Academia}

As Tom Keenoy (2005), Heather Menzies and Janice Newson (2007), Rosalind Gill (2009), Chris Lorenz (2012), and Paula Baron (2014), to name just a few, observe: Western time use and perception are limited to clock time as a result of the developments of industrialisation - and, as we may add, are further trimmed under neoliberal conditions (also Mountz et al., 2015). This rationalised and managerialist time-use radiates the ultimate utopian promise of efficiency as a core value, after the flexible office - now also via digitalised systems enabling cooperation on a global level. We can depart from the premise that, in general, managerially controlled working time is a variation of clock-time rationality: simply linear and logical, often geared to relatively short-term outcomes, and dismissing time complexities as not rational, or at best less important. This leaves out the intricate play of multiple, yet differing rhythms, durations, and sequences, outcomes, and beginnings of different timescales, and products that have short- and long-term effects on the different parts of academic work. Additionally, rational clock-time-oriented managerialism tends not to incorporate possible future effects (Sabelis, 2002) due to the notion that what has not happened yet cannot be measured, and thus drops out of the managerial scope. This goes for academics living (in) the present, and almost running-in-place, while pretending that the future is unknown or something to 
be dealt with only in futures when and if they present themselves (e.g. Clegg, 2010) - only then as a possible issue to deal with (a present future view, cf. Adam \& Groves, 2007). Accepting this as the mode of being for work and organisation, clock-time rationality presents itself as a sequence of sometimes overlapping but always forward-stretching tasks in linear forms, for example, piles of successive to-do-lists, a huge interest in planning, and a firm belief in growth as the main paradigm for survival. In my view, and in the view of a generation of time scholars combining the study of time with their own daily (embodied) experiences, this clock-related perception of time narrows down a wide range of other temporal possibilities, and perhaps necessities as well. Perceptions dealing with cultural difference, varying emotions, and more encompassing, bigger, or explicitly plural understanding of time(s), in which relationships between views, uses, and understandings of time prevail indeed require a more intense, sometimes confusing reflection on time in our daily lives, especially as these are not so straightforwardly captured in models, graphs, and measurements. However, a clock-time view helps increase the pressure put on people, because it leaves out the non-measurable everyday times that do not add to accountability but which we always feel. Clock-time rationality thus implicitly adds tasks and, at the same time, prevents one from looking beyond to-do-lists to other more encompassing, culturally diverse, interlinked, and mutually influencing modes of time and temporality, such as differences in energy, bodily markers like age, and the Eigenzeiten of people. As a result of fixation on clock time, we thus lose sight of time scales, different cultural norms regarding time, different paces and experiences of time, the role of duration, sequences, in the sum of timescapes: encompassing modes of time and their interrelationships (cf. Adam, 1998). Actually, the clock-time paradox where 'big' time is equated with clock time, and other times, broader temporalities are dismissed as less important - influences how we reflect on current developments in higher education, and thus also on possible other outcomes, other modes of organising, and other opportunities for curbing the downsides of the time regimes as brought forward by the limited focus of what is also called the metronomic character (Young, 1988) of present-day life and work.

Over the years, a plethora of studies have appeared about how time and time(s) are utilised by academics in contemporary university contexts and how time pressures lead to loss of quality via increased workloads and risky managerialism, the latter especially causing stress due to fragmentation of work and the rise of audit cultures and accountability cultures (Keenoy, 2005, Menzies \& Newson, 2007; Gill, 2009; Clegg, 2010; Ylijoki, 2013; Baron, 2014; Gill \& Donaghue, 2015; De Vita \& Case, 2016). It is not my intention to provide a full overview of the debate here, but it seems necessary to present some of the 
main arguments in order to have an idea of the debates and highlight some of their most important elements so as to grasp the complexity and the reach involved in looking at academic work from a timescape perspective.

\section{VIGNETTE 3: WORKING DAY}

Wake up shortly before seven - startled and with something stinging in my head. What again? - Oh, yes, the pile of manuscripts to be processed. Processing manuscripts, some 120 per year, goes with the position of being EC for one of the journals. Does not pay, is not calculated anymore, but the workload is increasing. Brain active in seconds. Get up; want that pile done before turning to writing that article.

Breakfast, bread and cheese, coffee and a smoothie, while reading the newspaper of today. Computer is starting up. Late messages from colleagues, and some early ones from that one colleague who manages to only process his mail in the morning. Before long, it is og:0o - head is working, on top of things. Already handled two requests from students, engaged in an ongoing debate over teaching reform and organisational (department) politics, and looked at flights for next month.

Message from dean comes in. Make an appointment for next week. Don't forget to email thesis students. Make a list for today. The list will probably swallow up the rest of the week. Mails, phone calls, reading, reviewing and having a look at a $\mathrm{PhD}$ manuscript. Get those little things out of the way - yet, when done, a large part of the day is over.

(IS - Spring 2016 - personal diary)

The overall picture is not a happy one. Most authors who have done research into the ins and outs of changing time use and perception in higher education and academic life agree on the need for analysis of the effects of neoliberalisation, with as its main effect a change in the character of academic work from process to project driven (Ylijoki, 2013; 2016), the first step in losing out on embodied, diverse, and not-always-accountable time use. But some also point to implicit health risks via 'hidden injuries' in the current systems (Gill, 2009; Gill \& Donaghue, 2015), and the effects of increased stress on content and context of our work (Baron, 2014). Additionally, Sue Clegg (2010) demonstrates how the time use currently imposed on academics reveals short-term characteristics aimed at stimulating ever faster cycles of academic production, both in teaching (students) and in research pursuits (journal articles). This assumes that there is a market for knowledge that determines the inner processes of academia - and this market obviously demands more or less direct return on 
its investment. Academic knowledge production as a commodity, a tradable goal in itself and generating profit, entails short-term orientation by its very nature. And a short-term, almost metronomic production of articles, project grants, and student output accelerates the flywheel of academic life. But not just that, it also extends fragmentation in academia itself. With a given tact on article output, longer-term work is discouraged. And the 'lottery' traits of project grant application (without which no academic these days gets a promotion) additionally adds to cutting corners and possibly desperate moves to... cut out time for the really interesting work. What about sustainable, long(er) term knowledge that requires other timescales for observing societal phenomena? What about time for reflection to include both past and future issues? What about bigger relationships and interlinkages in thinking if we produce in increasingly standardised formats? It seems important to look at what we lose by faster production - and what we can gain by at least a flexibilization of strict and general output demands.

\section{VIGNETTE 4: HOLIDAY}

Valorisation of results for the last batch of exams is due this week.

Due to a tight annual schedule (this is a summer holiday week), there is no other option than combining a holiday in Croatia with a little work.

Search a site with good Internet, close to the reception of the campsite.

Adolescents there: playing games and keeping in touch with their peers elsewhere in the world.

I sit down on my towel, open the laptop, and start working. It is a hot day; I hear the sound of children playing and the drum of waves in the distance.

Focus required; the university's system needs a lot of reloading pages before all the steps are done.

And yes, it takes a lot more than the envisioned hour. Lunchtime passes before I shut down.

Hopefully there will be no errors.

Within the hour, students' queries start coming in on the phone, I decide to have no Internet for the next two days.

(IS - personal diary, summer 2017)

Ylijoki (2013) identifies another temporal trait; one of the consequences of marketization and McDonaldisation is that academics first work hard to get 
the admin. out of the way before turning to the 'core business', meaning the joy of reading, reflecting, and writing, not just of research but also of students' work, and taking time to deepen discussions. 'Getting the admin. out of the way' tends to take more and more time, and of course this causes stress and frustration leading perhaps to even less time for the desired academic tasks. As administrative duties increase, including disruptions via digitalisation, academics end up working ever longer hours, because they get to 'the real work' later; and this leads to the conclusion that universities tend to increasingly exploit staff engagement. Administrative personnel (support staff, secretariats, policy-makers) often get annoyed when 'academics take their time'. But just one look at the amount of time one spends on emails or journals makes it fairly apparent that $24 / 7$ has been the norm for a long time now, and that 'smart working' adds to the pressure and is nothing new (cf. Keenoy, 2005). Support staff, however, are also under pressure via project obligations involving output and via the audit culture's ongoing new demands. The rise of different temporal demands (regimes) is one of the reasons why it has taken so long for the two groups to join together to protest against mounting institutional pressures.

In 2004 we carried out a small explorative research in my own faculty of social sciences. ${ }^{6}$ It turned out that the first cracks due to time pressure and mismatch between academics and support staff were visible at the time. The temporal patterns of working days between the two groups of colleagues were totally different. Due to the new digital systems, we could trace what these patterns were and how different time regimes served in miscommunication between staff and academics. Academics would mainly spend time at the university (buildings) for teaching, meetings, and the odd chat with colleagues. Staff would, as ever, work their nine-to-five, or eight-to-six working hours; they would be irritated by academics 'taking their time' and coming in, for instance, by eleven o'clock. What they did not observe were the emails late at night and the deadline-driven articles sent in the early morning hours. Staff suffered from the then-rising workload due to the combination of digitalisation of work coupled with the new form of accountability and control (Keenoy, 2005; Keenoy \& Seijo, 2009; Clegg, 2010). Academics then still enjoyed the rising options coming from the chance to work from home and the new opportunities for

6 The report Werkdruk FSW/Workload FSC, 2004, Cootje Loggers \& Ida Sabelis, was never externally published but is available upon request from the Faculty of Social Sciences, VU Amsterdam. A next check on the situation was planned a couple of years later, but not granted by the faculty management. 
worldwide cooperation with colleagues (see also Menzies \& Newson, 2008). However, the different paces and rhythms of work were not really seen as different in terms of time(s) - the presentation of our small-scale research results before the faculty population produced at least exchange of habits and indeed triggered mutual understanding for diverse work practices and times. However, the eye-opening effect of this small-scale research soon faded, and what remained was the frustration of not being able to synchronise work processes, which in turn led to more 'systems' being introduced (digital diaries, for instance) in order to keep track of what people were doing and where. Additionally, planning cycles became more visible and important - these would also cover larger timescales, as planning demands more precision and resilience to be taken into account (literally).

Paula Baron (2014) argues how academics' time use - in keeping with the Bildung concept - should be task-oriented, which is actually a craft, and crafts require various time dimensions. This is quite contrary to the fragmented, industrial image of production, be it that historically there seems to be a nice parallel in the development from time orientation to clock-time compliance under industrial pressure (Elias, 1982; Virilio, 1986; Zerubavel, 2012). Our headand-hand-work to produce academic quality requires a lot of time in order to bring to the fore the proper skills, to develop programmes, to teach, to study, and to produce outstanding research. Our products, or output, take different amounts of time, and different levels of intensity and product quality, to create a valuable, transferable entity. This requirement cannot be met, for instance, by the present three-year $\mathrm{PhD}$ programmes for ever younger students; it is counterproductive for the annual demands involving journal production and it undermines the rhetoric of institutional brochures that tout their lofty mission statements of 'excellence'. Sue Clegg (2010) presents another angle on this by stressing the present-future character of contemporary university education. This implies that the projected image of university output is geared towards short-term results, towards 'timescapes of employability' - and this produces another case of TINA in which employability is core. This means that employability, providing instant use for the labour market, has become more important than a future present notion of academia, for example, with a long-term orientation and a fuller or wider idea of accompanying young people in a search, an adventure of science and intellectual development, in order to become resilient, creative, and flexible citizens prepared for diverse future options. The nature and purposes of the modern university have been substantially reworked, encompassing not just a reductionist discourse of employability but fundamental shifts towards what Slaughter and Rhoades (2004) describe as 'academic capitalism', and Marginson and Considine (2000) as the 
'enterprise university' - no need stressing the metaphor of MacUniversity (Parker \& Jarvey, 1995; Ritzer, 1996).

Yet, these observations address daily work in higher education, and only hint at the underlying power processes at work. For the latter, we can look at the work by Ulrike Felt (2009). Departing from four narratives of time, she analyses the complexity of academic timescapes and demonstrates how hegemonic time regimes prevent re/action of the actors involved. According to Felt temporal regimes governing contemporary academia build an invisible infrastructure guiding the ways in which we know and the kinds of lives we can have in academic environments (Felt, 2009, p. 130) And Felt elaborates: '...this allows us to think of higher education as a set of nested relations between different temporalities in which change happens at different rates' (Felt, 2009, p. 132). Finally, this reveals how landscapes of higher education are deeply intertwined with timescapes and how researchers have to be understood in terms of their local embeddedness in an environment of ongoing processes of change in different temporal, material, and spatial dimensions.

\section{VignetTe 5: IMPROVISATION ON THE Digital ClasSROOM}

Digitalisation projects are always announced with the promise to make our lives easier: work faster, gain more time for other things, liaise all over the world, and enjoy the comfort. Grading, controlling assignments, keeping track of results, what have you - we don't need piles of paper but can do it all online. Students can immediately see the feedback on their work. Peers can control the grading process. Flip-the-classroom provides students with exactly what they need to know - and management can control teaching processes to manage the next peer control of education programmes. But in whose time do we learn to work with the software? Where does the saved time go? And how do students benefit from online teaching where individualisation demands personal contact?

Last year, I returned to the black-board and chalk system - by providing students with half of a class' information on a note-sheet an hour before class, so that they need to make their own notes during a lecture, while I complete notes on the (black or white) board. Students reported that this requires another type of involvement and mental activity, by which they had to think themselves, instead of just consuming. They reported that this enhanced their capacity to remember what was said in class.

IS - personal diary, 2017 
So, what about the current state of time, acceleration, workload, and a future image of where we are heading, towards or from the academic office? The disappearance of set working times and spaces, as so present in the observation in About Smith, have also appeared in academic life. Instead of escaping from the controlled office, including the total and even inner control of times, we have moved towards an open and flexible yet also highly controlled virtual office. It is my contention that this is a highly contradictory development of academic work over the last decades. Our work has become rationalised under novel forms of not-always-visible control via new ways of rationalising both offices and what has replaced offices, the digitalisation of work. May we state that academic work had also become fluid following Bauman's (2000) understanding? Are we '...just a piece of fiction-writing away from a non-fictitious dilemma exposed by Aldous Huxley and George Orwell, and (...) reinterpreted by (...) Michel Foucault...' as Bauman and Donskis argue in their last book, Liquid Evil (2016, p. 146)?

Digitalisation has brought huge benefits along with it, like cooperation on a global level, fast exchange with colleagues wherever they are, and the option to work whenever we feel inspired. But that option at the same time became imperative, as the radiating panorama of global academic life and education apparently blended out the risks. The reflexive consequences of these developments, often appearing later than the benefits, have not been highlighted as often as the downsides. This may well be due to fragmentation of effects; as Menzies and Newson (2007) pointed out, the possibility of being online soon turned into a necessity to browse the web and to be always on. What made us not see that development coming? One answer is that change never happens as a straightforward process but is bridled with diverse temporalities; it happens in different timescales of effect and reverberation. And it happens with different effects for different people, thus partly preventing collective action, as the need for action occurs in different times and situations. Acceleration can bring short-term benefits that are harvested before the downsides become apparent, and the downsides work out differently for people doing different tasks. And of course, often, as with burnout and other structural effects that take a long time to appear, it is very difficult to rationally track down the causes of the damage. ${ }^{7}$ It is in this context that Ulrike Felt's (2009, p. 59) call for a chrono-political analysis becomes important. Forging an analysis in which

7 This parallels the pollution debates in the natural (sustainability) sciences, as in Kümmerer's (1996) work on toxic matter in the environment, which built the foundation for developing 
times and organisational politics are considered simultaneously, as temporal regimes, brings to the fore not only the power dimensions at work but also and especially the fragmentation of interests preventing a coherent diagnosis. While we take time for granted (Adam, 1998), we do not see the workings of intricate time control (Felt, 2016, p. 132ff) especially not in its multiplicity and the different time scales linked up in systems of (managerial) power.

Maybe some of us have more influence on our own working conditions than others, especially in terms of the time = money mantra. But most of us can only comply with what is framed as progress and efficiency, leading to more output and more administrative and digitalised tasks. Can we detect a specific kind of TINA here? The There-Is-No-Alternative stamp on our time, as originally promoted by Margaret Thatcher, indicates that '...that there is no reality outside the free market, individualisation, deregulation, and dissemination...' (Donskis, 2016, p. 134). How ironic that the utopia of the free market should lead to loss of choice - and how limiting that planning and control should pervade all areas of development, for students and academics alike.

My personal inclination is still to pursue the question of why there is currently such a lack of interest or motivation on the part of university colleagues at all levels in terms of reflecting on the time spent on learning, education, and future conditions, on the one hand, and how knowledge should be developed, on the other. In other words: why does nobody seem to bother about what knowledge is developed and 'produced' under current clock-time-inspired regimes as long as the output criteria are met? Why do we not question the usefulness of knowledge and academic attitudes apart from meeting the audit criteria? And how come we do not interfere or protest when we see losses and risks in the current system? Under neoliberal rule, or TINA, the reasons for this are part of the same regime that promotes the linear, compartmentalised mode of temporality on daily academic work. Clock-time managerialism is, in a sense, simple, measurable, and plannable, and with that quality it provides a kind of certainty and reliability that feeds well into managerialist cultures, no matter the organisational or individual effects. If The System becomes more important because of its auditability, all else becomes insignificant. Acceleration and commercialisation of the academic industry have caused increased anxiety and have rendered academics cautious, toothless, and small, while consuming their time to the point where they believe their work to be the only Zeitgeber in their lives. During a visit to Kaunas University in October 2015, colleagues would approach me after my lecture on academic time to tell me how

the concept of timescales [toxic matter in the environment may take up to thousands of years to produce its negative effects]. 
truthfully and recognisably I had pictured their situation, and it was only then that I fully comprehended, really felt, how individualisation works: it took a fairly simple message to realise that the pressures of time we feel should not be an individual responsibility. Gill and Donaghue (2015) present the growing evidence of unease and desperation to be seen in blogs and forums. It becomes acutely visible that time pressure serves two masters: on the one hand, coupled with individualisation, not meeting the demands of the pressure it is characterised (and internalised) as an individual shortcoming, for instance via output demands and the prevalence of research over teaching. On the other, it leads to the trend of people 'running in place', with no time to reflect on what is actually going on, let alone to take collective action against the increased pressures. And this is exactly the message that lies at the foundation of Bauman and Donskis' (2013, pp. 96-97) argument: be careful not to lose your sense of morality because living a life of fear and forced compliance as a result of a lack of (broad) knowledge and less and less time to develop that knowledge results in increased ignorance, impotence, and humiliation. It is in this situation that we lose our ability to comprehend a broadened time horizon and maintain our capacity to use our time effectively, not in an economic sense but as a measure of human proficiency. The control systems have become our own personal robots. We become, however linked to global communities, caught up in our own individual time cubicles that float around like juggling balls of a managerial time-provider, a global belief in the rationality of academic life.

Post script: writing this chapter was a fair example of the TINA character of academic work. Essay-like reflections for an edited volume are not what our audit-culture values. And therefore, it takes sometimes a long, long time before a publication can be finalised - especially if it does not 'count' in the system.

\section{Vignette 6: On FAding ENERgy}

...It is not the amount of time spent, but the number of times you have to turn your head around for diverse tasks. Reading an article is different from reviewing one. Grading a research proposal requires a different level of attention from replying to a list of emails. And, if on one morning the to-do list requires that many different tasks, the energy flows away in the process of adapting to the different kinds of energy those tasks need and consume. Head spinning after a few hours. Cannot grade, think, and write all at the same time.

IS - diary February 2018 


\section{References}

Adam, B. (1995). Timewatch. The Social Analysis of Time. Cambridge, Polity Press.

Adam, B. (1998). Timescapes of Modernity: The Environment and Invisible Hazards. London, Routledge.

Adam, B., \& Groves, C. (2007). Future Matters: Action, Knowledge, Ethics. Leiden, Brill.

Baron, P. (2014). Working the clock: The academic body on neoliberal time. Somatechnics, 4 (2), 253-271.

Bauman, Z. (2000). Liquid Modernity. Cambridge: Polity Press.

Bauman, Z., \& Donskis, L. (2013). Moral Blindness: The Loss of Sensitivity in Liquid Modernity. Cambridge, Polity Press. (especially chapter 4).

Bauman, Z., \& Donskis, L. (2016). Liquid Evil: Living with TINA. Cambridge, Polity Press.

Clegg, S. (2010) Time future - the dominant discourse of higher education. Time \& Society, 19(3), 345-364.

Davies, B., Gottsche, M., \& Bansel, P. (2006). The rise and fall of the neo-liberal university. European Journal of Education, 41(2), 305-319.

De Vita, G., \& Case, P. (2016). The smell of the place: Managerialist culture in contemporary UK business schools. Culture and Organization, 22(4), 348-364.

Donskis, L. (2016). Three modern sensibilities: Machiavelli, Shakespeare, and more. Deeds and Days, 66, 121-135.

Elias, N. (1982/1985). An Essay on Time. Amsterdam, Meulenhoff.

Felt, U. (2009). Taking European knowledge society seriously. In Science et devenir de l'homme. 59, Fascicule thématique Science in Society: Dialogues and Scientific Responsibility. European Conference, Paris, France, 2008-11-24. MURS. Retrieved from http://ec.europa.eu/research/science-society/document_library/pdf_o6/european -knowledge-society_en.pdf.

Felt, U. (2016). Of timescapes and knowledgescapes. New Languages and Landscapes of Higher Education, 129-148.

Gill, R. (2009). Breaking the silence: The hidden injuries of neo-liberal academia. Secrecy and silence in the research process. Feminist Reflections, 228-244.

Gill, R., \& Donaghue, N. (2015). Resilience, apps and reluctant individualism: Technologies of self in the neoliberal academy. Women's Studies International Forum. http:// dx.doi.org/10.1016/j.wsif.2015.06.016.

Keenoy, T. (2005). Facing inwards and outwards at once: The liminal temporalities of academic performativity. Time \& Society, 14(2-3), 303-321.

Keenoy, T., \& Seijo, G. (2009). Re-imagining e-mail: Academics in the castle. Organization, $17(2), 177-198$.

Kümmerer, K. (1996). The ecological impact of time. Time \& Society, 5(2), 209-235.

Lemke, J.L. (2001). Articulating communities: Sociocultural perspectives on science education. Journal of Research in Science Teaching, 38(3), 296-316. 
Lorenz, C. (2012). If you're so smart, why are you under surveillance? Universities, neoliberalism, and new public management. Critical Inquiry, 38(3), 599-629. https:// doi-org.vu-nl.idm.oclc.org/10.1086/664553.

Marginson, S., \& Considine, M. (2000). The Enterprise University: Power, Governance and Reinvention in Australia. Cambridge, Cambridge University Press.

Menzies, H., \& Newson, J. (2007). No time to think: Academics' life in the globally wired university. Time \& Society $16(1), 83-98$.

Menzies, H., \& Newson, J. (2008). Time, stress and intellectual engagement in academic work: Exploring gender difference. Gender, Work \& Organization, 15(5), 504-522.

Mountz, A. Bonds, A. Mansfield, B., Loyd, J., Hyndman, J., Walton-Roberts, M., Basu, R., et al. (2015). For slow scholarship: A feminist politics of resistance through collective action in the neoliberal university. ACME: An International Journal for Critical Geographies, 14(4), 1235-1259.

Nowotny, H. (1992). Time and social theory towards a social theory of time. Time \& Society, 1(3), 421-454.

Nussbaum, M. (2010). Not for Profit: Why Democracy Needs the Humanities. Princeton, NJ, Princeton University Press.

Oelkers, J. (1999). The origin of the concept of 'Allgemeinbildung' in 18th-Century Germany. Studies in Philosophy and Education, 18(1-2), 25-41.

Paolucci, G. (1996). The changing dynamics of working time. Time \& Society 5(2), $145^{-167}$

Parker, M., \& Jary, D. (1995). The McUniversity: Organization, management and academic subjectivity. Organization, 2(2), 319-338.

Ritzer, G. (1996). McUniversity in the postmodern consumer society. Quality in Higher Education, 2(3), 185-199.

Roderick, I. (2016). The politics of office design. Journal of Language and Politics, 15(3), $274-287$.

Rosa, H. (2003). Social acceleration: Ethical and political consequences of a desynchronized high-speed society. Constellations, $10(1), 3-33$.

Sabelis, I. (2002). Hidden causes for unknown losses: time compression in management. In Whipp, R., Adam, B., \& Sabelis, I. (eds.) Making time: Time and Management in Modern Organizations (89-103). Oxford, Oxford University Press.

Slaughter, S. \& Rhoades, G. (2004). Academic Capitalism and the New Economy. Markets, State and Higher Education. Baltimore, The Johns Hopkins University Press.

Van der Pijl, K. (2006). A Lockean Europe? New Left Review, 37, 9-37.

Virilio, P. (1986). Speed and Politics. An Essay on Dromology, New York, Semiotext(e).

Ylijoki, O.-H. (2016). Organising logic: Project time versus process time in the accelerated academy. Impact of Social Sciences Blog.

Ylijoki, O.-H. (2013). Boundary-work between work and life in the high-speed university. Studies in Higher Education, 38 (2), 242-255. 
Young, M. (1988). The Metronomic Society. Cambridge MA, Harvard University Press. Zerubavel, E. (2012). Time Maps: Collective Memory and the Social Shape of the Past. Chicago, University of Chicago Press.

\section{Further Reading}

http://blogs.lse.ac.uk/impactofsocialsciences/the-accelerated-academy-series/ (March 2018).

Gibbs, P. Ylijoki, O.-H., Guzmán-Valenzuela, C., \& Barnett, R. (eds.) (2014). Universities in the Flux of Time: An Exploration of Time and Temporality in University Life. London, Routledge.

Ylijoki, O.-H. (2016). Projectification and conflicting temporalities in academic knowledge production. Teorie vědy/Theory of Science, $38(1), 7-26$.

Ylijoki, O.-H. (2014). Conquered by project time? Universities in the Flux of Time: An Exploration of Time and Temporality in University Life. London, Routledge, 94-107. 